\title{
Tecnologias do gênero: media e mercados de drogas ilegais
}

\author{
Lúcia Lamounier Sena ${ }^{1}$
}

Resumo: O objetivo deste artigo é estabelecer um possível diálogo entre a perspectiva de tecnologias de gênero, proposição do campo teórico feminista, e o sistema midiático. O cruzamento desses campos visa construir um referencial teórico e metodológico para uma análise sobre os argumentos que circulam nos media relativos à participação das mulheres nos mercados de drogas ilícitas no Brasil. A questão que se coloca é a relação entre as recorrentes representações publicizadas, de forma específica nos enquadramentos jornalísticos, e a constituição de um sujeito político: "a mulher no tráfico". Para tanto, a discussão faz referências a uma análise inicial sobre a cobertura jornalística da capital mineira na primeira década dos anos de 2000.

Palavras-chave: Gênero, Sistema Mídia, Tráfico Ilegal de Drogas.

Abstract: The purpose of this article is to establish a possible dialogue among the perspective of gender technologies, the feminist theoretical proposition field, and the media system. The intersection of those fields aims to build a theoretical and methodological framework for an analysis of the arguments that circulate in the media regarding the participation of women in illicit drug markets in Brazil. The question that arises is the relationship among recurrent publicized representations, specifically in journalistic frameworks, and the constitution of a political subject, "women in drug trafficking". Therefore, the discussion refers to an initial analysis of research on media coverage of the state capital of Minas Gerais in the 2000's.

Keywords: Gender, Media System, Illegal Drugs Trafficking.

\section{Introdução}

Entendida como processo de significação, a diferença é estabelecida através das constantes disputas travadas em torno da hegemonia de sentidos. Inscreve-se nas práticas, nos discursos e instituições, podendo definir exclusões ao posicionar o diverso como desigual. Os fundamentos políticos da diferença evidenciam-se na constituição de categoria social de um sujeito político (SCOTT, 1990; MISSE,1999; AVTAR, 2006). Tendo em visa esses pressupostos, este artigo propõe uma reflexão sobre os media, entendidos como um dos operadores políticos da diferença.

\footnotetext{
${ }^{1}$ Mestre em Comunicação Social pela UFMG e doutora em Ciências Socais pelo Programa de Pós-Graduação em Ciências Sociais da PUC Minas. Professora Adjunto IV do departamento de Comunicação Social da Pontifícia Universidade Católica de Minas Gerais. Coordenadora e Pesquisadora do Centro de Estudos e Pesquisa em Segurança Pública - CEPESP - do departamento de Ciências Sociais da PUC Minas. E-mail: 1lsena.bh65@gmail.com.
} 
Os midia procedem a um fazer especializado e credível, ainda que constituído por um ambiente recortado por atores em posições, plataformas e linguagens diversas, sobretudo a partir do fenômeno das medias sociais, para dizer sobre o mundo. Daí a necessidade de entendê-los como um campo de luta e disputa política, um campo relevante na composição, proposição de conteúdos e enquadramentos dos argumentos lançados e presentes no debate público (MAIA,2009). De forma específica, para o tema deste artigo, há a necessidade de indagarmos sobre a relação dos media com os argumentos processados nos mais diversos campos sociais, dos mercados ilegais de drogas. Particularmente, as proposições em relação à participação das mulheres nesta atividade.

No caso dos jornais impressos, os conteúdos e enquadramentos mais recorrentes nas notícias e reportagens sobre a participação feminina em redes de comercialização de drogas ilegais têm participado na construção dos significados relativos a uma categoria gendrada: "a mulher no tráfico." Assim, o objetivo deste artigo é estabelecer um possível diálogo entre a perspectiva de tecnologias de gênero, proposição do campo teórico feminista (DI LAURETIS, 1987) e o sistema midiático. O cruzamento desses campos visa construir um referencial teórico e metodológico para a reflexão sobre a abordagem jornalística relativa à participação das mulheres nos mercados de drogas ilícitas, no Brasil, na primeira década dos anos 2000. A questão que se coloca é a relação entre as recorrentes representações publicizadas de forma, específica, nos enquadramentos jornalísticos, e a constituição de um sujeito político: “a mulher no tráfico" ${ }^{2}$.

Ainda que a questão midiática não tenha sido objeto da tese, durante o trabalho de campo foi recolhido, de forma aleatória, um conjunto de matérias publicadas em jornais mineiros, entre os anos de 2006 e 2010, que abordavam a participação das mulheres no tráfico. Aqui, retomo a análise desse material, ainda em fase inicial, complementando-o com um material que está sendo levantado e analisado ${ }^{3}$. Para o argumento apresentado neste texto não há uma análise global do material empírico, uma vez que esta análise ainda se encontra

\footnotetext{
${ }^{2}$ Este texto se insere no universo de discussão sobre a participação de mulheres em redes distintas de comercialização de drogas ilícitas, em Belo Horizonte e sua Região Metropolitana, realizada no âmbito da minha tese de doutoramento no Programa de Pós-Graduação em Ciências Sociais da PUC Minas, defendida no ano de 2015.

${ }^{3} \mathrm{O}$ material completo, em fase de coleta e análise, fará parte de uma pesquisa sobre os 20 anos da cobertura jornalística sobre o fenômeno do crack, que realizamos em parceria com professor Mozahir Salomão, coordenador do grupo Mídia e memória: construção de identidades (PUC Minas/CNPq).
} 
em processo. Algumas matérias são citadas no intuito de exemplificarem o contexto da discussão.

Este artigo está dividido em três partes. Na primeira, apresento alguns pontos do debate sobre as diferenças de gênero e crime, com ênfase especial no debate sobre mulheres e criminalidade. Na segunda parte a discussão centra-se no conceito de tecnologia de gênero e o sistema mídia, procurando estabelecer pontos de relação entre as duas abordagens. Na última parte faço algumas considerações sobre os rumos da pesquisa a partir dos argumentos apresentados.

\section{Mulheres e Tráfico de drogas: diferenças no contexto de um debate}

No texto introdutório da obra História das Mulheres no Ocidente, Georges Duby e Michelle Perrot (1990), os autores indagam, de maneira irônica, se seria possível ou se haveria realmente uma história das mulheres para ser narrada. Esses personagens sem voz, não contabilizadas nos grandes feitos que "fizeram e fazem a história", devotadas ao recôndito dos lares e dos ofícios sagrados da maternidade ou, quando atuantes, coadjuvantes dos heróis, dos bandidos, suas amantes ou carpideiras.

No caso brasileiro, as condições de marginalização vivenciadas pelas mulheres tornaram-se objeto de estudo reconhecido e valorizado como direcionador de uma abordagem sobre a história das mulheres e das políticas públicas. No entanto, as situações de transgressão feminina são tratados como extraordinárias, sobretudo quando se trata de atividade criminosa de grande visibilidade midiática, como é o caso do tráfico de drogas. Neste delito específico, os estudos ainda são escassos e as mulheres são, com muita frequência, analisadas sob a ótica da pobreza, da submissão às agruras dos amores bandidos, envolvidas com o tráfico como decorrência das dificuldades para inserção no mercado formal de trabalho, ou analisadas sob a ótica da violência imposta pelos parceiros ou filhos. O protagonismo feminino é raramente abordado.

No campo da criminologia feminista, o debate sobre a diferença de gênero no crime tem nos trabalhos de Freda Adler, Sister on Crime (1975) e Rita James Simon, Women and Crime (1975) referência inicial. A perspectiva do "shade side of liberation" é de que haveria uma associação entre o movimento de liberação feminina e o incremento das taxas da 
criminalidade feminina, inclusive nos crimes violentos, então na cena midiática, nos Estados Unidos. Essa evidência foi amplamente refutada, tanto pelo acentuado ponto de vista político, como pela falácia empírica desse argumento (STEFFENSMEIER, 1996; STEFFENSMEIER; CLARCK 1980; CHESNEY-LIND, 1986; PARENT, 1992).

No debate que marcou a questão da diferença entre homens e mulheres no crime, nos anos de 1980/90, com destaque específico para as vertentes norteamericanas, há uma relativa convergência na afirmação das dimensões essenciais relativas às assimetrias de gênero. Nessas teorias, ainda que entendendo o gênero como uma construção social, marcada por um sistema sexo/gênero, os atributos essenciais do gênero são afirmados como capazes de explicar os efeitos diferenciais dessas dimensões no crime. O elemento que persiste, neste campo teórico, é a crença em uma essência feminina, social e/ou biologicamente constituída, cuja incidência nas atividades criminais revelar-se-ia em um substantivo e específico padrão de ação criminal, tomando-se a substância como a variável que explica esse padrão.

A essencialidade própria de um ser, tido como portador de uma identidade de gênero, supostamente explicaria as formas de agir e os sentidos de certas práticas (e não outras quaisquer), que se estabelecem no âmbito específico de uma dinâmica criminal. Essa perspectiva de análise do crime, como gender-specific theories, na forma de entender um sistema de dominação, sobre o qual se erguem as normas sociais de gênero explicativas das diferenças femininas e masculinas no crime, tem, na proposição apresentada por Darell Steffensmeier \& Emilie Allan (1996), uma referência exemplar.

O conceito de organização de gênero, uso da dicotomia morfológico-sexual humana, como um parâmetro sobre os quais são legitimadas as diferenças sociais, é incorporado pelos autores no sentido de que, ao normalizar comportamentos e identidades, a organização de gênero apresenta-se nas regulações institucionais, nas relações sociais e na definição dos padrões de socialização diferenciados. Seriam esses padrões as clivagens práticas e morais do que é masculino (que se confunde com uma representação de crime) e do que é feminino (que se distingue de crime). Essa distinção incidiria nas diferenças presentes nas probabilidades de gênero de determinadas práticas, sendo a ausência das mulheres nos crimes violentos a intenção da prescrição de uma teoria explicativa de gênero e criminalidade proposta.

Em meados da década de 1990, as abordagens sobre gênero e criminalidade vem à tona, fortemente marcadas pela suposta "estrutura de oportunidades ilegais", aberta para as 
mulheres através de uma atividade específica - o tráfico de drogas - oportunidade advinda da expansão do crack no mercado das drogas ilegais nos EUA, nos anos 80. O debate ora apresenta um cenário de permanências no institutional sexism underworld (MAHER, 1997), ora afirma um quadro de mudanças (FAGAN, 1994), resultante da fragilização do domínio masculino nos mercados das drogas. Essa fragilização foi relacionada a uma interação entre o modelo de negócio de uma nova droga, o crack, e um contexto social, econômico e político em que se verificou uma ampliação do desemprego, do encarceramento e das mortes violentas dos jovens masculinos de grupos social, espacial e racial/etnicamente segregados (BOURGOIS, 1989; FAGAN, 1994; JACOBS, 1999; WACQUANT, 2008).

No Brasil, no final dos anos 2000, os estudos sobre a criminalidade que tangenciam o tráfico de drogas trazem o conceito de "reconfiguração dos ilegalismos", contexto em que, seguindo uma tendência global, reativam-se as prisões não somente como uma referência político-disciplinar em temos do recorte do espaço, dos agentes e das transgressões (RUGIERO; SOUTH, 1997; WACQUANT, 2008; FELTRAN, 2011; TELLES, 2010; 2011; MISSE, 2010;). Nesse cenário ampliaram-se os atuais estudos sobre gênero e criminalidade no Brasil e estudos prisionais femininos que perscrutam as configurações, ajustes e contingências de sentidos de diferença, agenciados pelas mulheres (LIMA, 2006; LAGO, 2012; BUMACHAR, 2012; PADOVANI, 2013; SENA 2015).

A ampliação do interesse pelo tema diz respeito a uma tendência global seguida pelo sistema prisional brasileiro que reafirma a natureza político-institucional das prisões efetivando a diferença em temos do recorte do espaço, da especificação dos agentes e do perfil das transgressões (WACQUANT, 2008). Isso pode ser lido no quadro da população encarcerada no Brasil. Ao final dos anos 2000, nesta população, no Brasil, predominavam os homens $(93,4 \%)$, enquanto as mulheres eram apenas 6,6\%. Na categoria tráfico de entorpecentes, de 12,4\%, do total da população carcerária, em 2006, o tráfico passou a representar 24,4\% em 2011 (taxa de crescimento de 164,9\%) ${ }^{4}$. Nas mudanças do perfil dos encarcerados, o destaque é para as mulheres. Se, em 2006, elas eram 25,5\% do total da população feminina, encarceradas devido a esse crime, em 2011, esse percentual passa a ser

\footnotetext{
${ }^{4}$ Para a categoria Tráfico foram somadas as categorias Tráfico de Entorpecentes e Tráfico Internacional de Entorpecentes Os dados prisionais aqui apresentados, e elaborados pela autora, foram baseados nas informações disponibilizadas pelo Sistema Integrado de Informações Penitenciárias - InfoPen, no portal do Ministério da Justiça, Disponível em http://portal.mj.gov.br. Acesso 10 de dezembro de 2012.
} 
de $49,7 \%$. Isso significa que, enquanto para os homens registrou-se uma taxa de crescimento de 161\%, no caso das mulheres essa variação foi de 192,6\%. E de que forma esse crescimento que foi sendo publicizado pelos media como um fenômeno do "avanço" das mulheres brasileiras na criminalidade relaciona-se a uma ideia do sistema mídia como um dos operadores de uma tecnologia de gênero?

\section{Tecnologia do gênero e o Sistema Mídia}

Abordar a perspectiva sistêmica dos $m e d i a^{5}$ como uma tecnologia do gênero é procurar estabelecer um cruzamento entre as implicações dos aparatos técnicos midiáticos, capazes de fazer emergir e disputar a visibilidade de um mundo de sentidos, e a perspectiva de gênero como "um elemento constitutivo de relações sociais fundadas sobre as diferenças percebidas entre os sexos" (SCOTT, 1990, p.14). Adotamos o ponto de vista de Scott, para quem as diferenças de natureza sexuada consolidam-se na diversidade do mundo material (objetos e espaços de diferença), do mundo simbólico (representações sociais), do mundo políticoinstitucional e sociotécnico, dimensões nas quais o poder fundamenta-se na lógica das hierarquias e posições sociais sexualmente diferenciadas.

Por tecnologia de gênero adota-se aqui a perspectiva de Di Lauretis (1990) que advoga que o gênero resulta de diferentes tecnologias sociais, tais como os discursos e práticas institucionais e cotidianas, as representações culturais, a hierarquização de gênero dos espaços físicos, dos espaços do trabalho e demais campos sociais. Incluem-se, aqui, o sistema mídia, entre outras tecnologias sociais. Através dos aparatos sociotécnicos os sujeitos são constituídos como diversos devido a uma natureza biológico-sexual. Para a autora, o gênero não deve ser entendido como uma propriedade presente no dimorfismo dos corpos, mas algo constituído como um efeito sobre essas diferenças nos corpos, nos comportamentos e nas relações sociais.

Fazendo um recorte específico das tecnologias sociais para o universo midiático, em quaisquer das suas formas, linguagens e plataformas, o "mundo" que é dado a ver é um

\footnotetext{
${ }^{5}$ Por sistema mídia adoto a perspectiva de Maia (2009): uma articulação institucional com interesses próprios que pressupõe autonomomização das relações; recursos para sua manutenção; funções específicas que atuam de modo relativamente independente e diferenciadas de outros; regras, rotinas e específica divisão de trabalho; liberdade de movimento em relação às forças de outros sistemas.
} 
sentido operado por uma técnica cotidiana de produção de um social partilhado. A despeito da relação desigualmente institucionalizada entre os produtores, a amplitude do acesso e produção de sentido dos conteúdos compartilhados, da sua aceitação, negação ou negociação (na perspectiva adotada por Stuart Hall, 1978) há uma realidade tecnicamente configurada e tornada pública. A publicidade do "mundo" estabelece-se pelo destaque diferencial de argumentos relativos aos sujeitos sociais e suas práticas referentes, estabelecendo, dessa forma, aquilo que Castoriadis (1988) chama do leigin, ou seja, figuras operantes do imaginário social, que realizam a noção de separação, reunião, identidade.

As práticas jornalísticas, essa "tecnologia do imaginário" como nomeada por Juremir Machado (2009), também são centrais na forma de operar uma construção dos espaços e identidades "gendradas", ou seja, marcadas por especificidades naturalizadas como diferenças de gênero (DI LAURETIS,1987). Essas especificidades são definidas em fronteiras (argumentativas, espaciais e simbólicas) em que se concebe nos fatos constituidores da realidade, tecnicamente operada, uma produção política dos sujeitos. No caso do tráfíco de drogas, são sujeitos identificados, principalmente, através das marcações de posições sociais de gênero: "Mãe e filhos são detidos"; "Dona de casa colocava o filho para vender drogas", são alguns poucos exemplos reveladores desse operador político.

O cenário social contemporâneo é inundado por uma profusão de interlocutores tecnicamente paramentados e capazes de se inserirem de forma e em posições diferenciadas, na amplitude de espaços de produção e deliberação pública. Nesse ambiente entrecortado pela produção e troca de argumentos advindos de matrizes e plataformas as mais diversas, poderíamos indagar: é pertinente falar do fazer midiático jornalístico como uma técnica relevante na construção de essencialidades políticas de gênero?

No estudo apresentado por Rousiley Maia et al (2015), os autores chamam atenção para as lacunas dos estudos que buscam o destaque dos enquadramentos midiáticos na opinião pública, no contexto contemporâneo hibrido e interconectado de media. Plataformas e enquadramentos concorrentes obliterariam as predominâncias de angulações, “(...) Ademais, no sistema interconectado de media, há maiores chances de "exposição inadvertida" a conteúdos dissonantes, mesmo quando os sujeitos não procuram por tais informações (BRUNDIDGE, 2010 APUD MAIA et al, 2015, p. 6).

\footnotetext{
${ }^{6}$ Títulos ou conteúdo de algumas matérias coletadas entre os anos de 2006 a 2009, no jornal O Tempo, versão
} online. Grifos nossos. 
No entanto, nos crimes relacionados ao tráfico de drogas a dissonância argumentativa é obliterada, dentre outras questões, pelo fato de ter sido um delito elevado à categoria de um crime de natureza mundial, combatido pelas pressões e por tratados internacionais, em nome de uma cruzada, dos quais o Brasil é signatário ${ }^{7}$. As matrizes midiáticas predominantes da abordagem sobre esse tema estão presentes em jornais impressos ou programas televisivos fortemente marcados por contratos de leitura popular. Não raro se dirigem às populações que são as principais vítimas da cruzada "War in drugs". Os enquadramentos mais recorrentes reforçam as posições morais de sentido desse delito e nada divergentes em termos dos significados divergentes de gênero.

O material, até então coletado na pesquisa, apresentou um conjunto de matérias de caráter meramente factual e que raramente chama para o debate, no sentido de uma proposição argumentativa. As universalidades essenciais das posições de gênero comandam a estruturação dos pronunciamentos presentes em todos os títulos até então analisados ${ }^{8}$. Esses enquadramentos são o ponto de partida dos conteúdos que são postos em circulação. Acrescese o fato de que essa temática têm presença marcante e quase exclusiva de editorias à cargo de homens, que devem pronunciar-se em relação a uma prática, o crime, que historicamente foi tida como uma seara do sujeito do masculino.

Os "constrangimentos da moldura", como especificado por Maurice Mouillaud (1997) em relação à produção dos enquadramentos, não são somente aplicáveis à dimensão isolada da experiência que deve ser publicizada. "Uma doméstica presa, acusada de atuar com o filho"; "Mãe e filho são detidos com drogas em Betim", implica no uso de um argumento diferencial de gênero (de natureza verbal, imagética e simbólica) cujos sentidos são relativos a um espaço e tempo sociais, que lhes são próprios. Como bem destaca Maia (2015), ao citar a perspectiva de Mutz (2006), os argumentos publicizados não necessariamente apresentam razões próprias, mas rearticulações políticas pré-existentes” (MAIA, 2015,p.4).

No exame de alguns pressupostos da teoria crítica habermasiana realizada por Nancy Fraser (1987), está presente um argumento da legitimidade do recurso ao particularismo dos

\footnotetext{
${ }^{7}$ Segundo estudo de Chagas e Ventura (2010) no Brasil atualmente estão em vigor 25 acordos bilaterais de cooperação técnica e/ou financeira internacional, relativos à Prevenção do Consumo e Controle do Tráfíco Ilícito de Entorpecentes e Substâncias Psicotrópicas, sendo 12 com países das Américas (9 na América do Sul), 5na Europa e um no Continente Africano.

${ }^{8}$ Este montante inicial diz respeito a somente um dos jornais coletados (O Tempo). A análise foi de 174 títulos com referência às mulheres, publicados entre o ano de 2006 a 2009.

${ }^{9}$ Títulos das reportagens analisadas no Jornal O tempo, entre os anos de 2006 a 2011. Grifos nossos.
} 
sujeitos do feminino nas disputas por voz nos embates púbicos. Essa questão traz à tona as desiguais posições das mulheres no acesso e controle sobre os meios de interpretação e comunicação relativos aos significados sociais sobre os corpos, as concepções de feminilidade, as necessidades e desejos das mulheres. As disputas da sociedade também são insumos inerentes ao processo de emolduramento, ainda que não, necessariamente, operados com racionalidade (SENA, 2012). Nesse sentido, os operadores midiáticos, são recursos fundamentais no caráter dos argumentos presentes nos processos de deliberação sobre as questões de gênero, de maneira particular sobre as questões das mulheres.

$\mathrm{Na}$ amplitude daquilo que se referencia como sistema media, permanecem as perícias capazes de “(...) rastrear, apresentar, evidenciar, representar, expor e, por meio de sua técnica, interpelar e assegurar-se de que se chega à verdade dos fatos" (MACHADO, 2009, p.14). Mas, evidentemente, a "verdade dos fatos" não é uma essencialidade à espera de ganhar aparência. O acontecimento tecnicamente produzido e emoldurado é, antes, uma forma de extrair atributos aos sujeitos e fatos, cuja essencialidade não lhes é inerente, mas realiza-se na própria técnica de publicizá-lo.

Se aceitarmos que o gênero é o sujeito em ato, conforme reinvidicado por Judith Butler (1987; 2011), o enquadramento midiático é um operador do emergir argumentativo sobre o gênero. É a instauração política de um sujeito, através das ações e argumentos destacados como lhes sendo, naturalmente, correspondentes. $O$ fato de alguém ser representado como masculino ou feminino subtende a totalidade dos atributos que compõem essa representação." (LAURETIS, 1990, pag.212). O título da notícia "Mães levam droga para filhos em Cadeia" 10 é um bom exemplo desse operador. O cerne da questão tornada pública é um sujeito biológico, sexualizado, institucional e moralmente referenciado na sua prática delituosa de gênero, e não, necessariamente, sobre um delito previsto no artigo 40 da Lei de Tóxicos $11.343 / 2006^{11}$.

Na referência ao sistema mídia como uma tecnologia produtora do sujeito do feminino nos mercados ilegais de drogas, aparentemente, o que se argumento aqui apresentado é um

\footnotetext{
${ }^{10}$ Título de uma matéria do jornal O Tempo, 2007. Grifos nossos.

${ }^{11}$ Art. 40: As penas previstas nos Artigos 33 a 37 desta Lei são aumentadas de um sexto a dois terços, se: III - A infração tiver sido cometida nas dependências ou imediações de estabelecimentos prisionais, de ensino ou hospitalares, de sedes de entidades estudantis, sociais, culturais, recreativas, esportivas, ou beneficentes, de locais de trabalho coletivo, de recintos onde se realizem espetáculos ou diversões de qualquer natureza, de serviços de tratamento de dependentes de drogas ou de reinserção social, de unidades militares ou policiais ou em transportes públicos.
} 
campo requentado das discussões sobre as representações e estereótipos femininos, abundantemente discutidos a partir dos estudos culturais nos anos de 1980 e, no caso brasileiro, a partir dos anos de 1990 (BUZZANESSI, 1990 APUD FREIRE FILHO, 2005). No entanto, o argumento inicialmente aqui esboçado não é sobre ausências ou deturpações das posições de gênero no crime. A reflexão proposta é sobre como as próprias formas de construir um argumento sobre o "crime" e de forma específica o "tráfico ilegal de drogas", as ações e os sujeitos que lhes são afeitos reafirmam as essencialidades de gênero. Nesse sentido, o sistema mídia mostra-se como uma eficiente tecnologia de trazer à tona um universo discursivo que reafirma as posições essencializadas de "mulher" e "mulher no tráfico".

\section{Considerações finais}

O destaque, aqui, é para a proposição dos media como uma tecnologia de gênero como uma diretriz importante para a análise do corpus de pesquisa eventualmente constituídos. Primeiramente a questão que se coloca é de que o campo dos media não deve ser tomado como um aparato sociotécnico maquiavelicamente construído para a dominação de gênero. No entanto, a centralidade desse campo nas representações sociais e argumentos que fazem circular não devem ser desconsiderada.

As posições derivadas das representações e argumentos constituidores dos limites corporais (uma mulher), das dimensões simbólicas e institucionais (mãe, doméstica, traficante) aprisionam não somente aquilo se nomeia como um homem ou mulher, mas os próprios termos em que o debate se realiza. As atribuições das posições sociais e significados diferenciais do gênero são vividas, não somente, na esfera da representação, do simbólico, mas como atributos encarnados pelos sujeitos como lhe sendo próprios. Mas essas articulações não são dadas somente pela dimensão técnica midiática. É uma constituição social do sujeito "gendrado". Mas, a despeito de preceder o operador midiático, tem no sistema mídia uma eficiente tecnologia política de gênero.

O caráter construído e não constitutivo dos sujeitos e do gênero tem nas representações sobre a criminalidade um campo privilegiado para os pronunciamentos sobre as supostas essências masculinas e femininas como sendo propícias ou avessas aos “desvios". 
Arriscaríamos dizer que o sistema mídia, também historicamente, é um lócus da constituição e reprodução dessa diferença. Essa é uma perspectiva metodológica importante para a reflexão sobre esse campo.

\section{Referências}

AVTAR, B. Cartografías de la díaspora: identidades en cuestión. Madrid: Maggie Schmitt y Traficantes de Sueños, 2011. cap. V.

BUTLER, J. Variações sobre sexo e gênero - Beauvoir, Wittig, Foucault. In: CORNEEL, Drucilla; BENHABIB, Syla (Coord.). Feminismo como Crítica da Modenidade. Rio de Janeiro: Rosa dos tempos, 1987. p. 139-153.

BUTLER, J. Problemas de gênero: feminismo e subversão da identidade. 4. ed. Rio de Janeiro: Civilização Brasileira, 2012. 236 p.

BUMACHAR, B. "Por meus filhos: usos das tecnologias de comunicação entre estrangeiras presas em São Paulo", Cogo, Denise;ElHaiji, Mohammed; Huertas, Amparo (org).Diásporas, Migrações, tecnologias da comunicação e identidades transnacionais. 1ed.Barcelona: Institutde la Comunicaió, Universitat Autònoma de Barcelona,2012, Vol.1 ,pp 449-468

CHAGAS, Fernanda Galvão Leite; VENTURA, Carla Aparecida Arena (2010), Cooperação internacional em prevenção do uso abusivo de drogas no Brasil SMAD, Rev. Eletrônica Saúde Mental Álcool Drogas (Ed. Portuguesa), v.6, n.1, Ribeirão Preto, pp. 1-20. Disponível em: $\quad$ http://pepsic.bvsalud.org/scielo.php?pid=1806697620100001\&script=sci issuetoc. Acesso em abril de 2014.

CHESNEY-LIND, M. Women and crime: the female offender. Journal of Women in Culture and Society. v. 12, n. 11, 1986. Download by JUSTOR, 23 Nov. 2013, p. 78-96.

DAILY, K.; CHESNEY-LIND, M. Feminism and criminology. Justice Quartely, Academy of Criminal Justice Sciences, v. 5, n.4, p. 497-538, 1988. Disponível em HeinOnline. Acesso em 18 de Fev. 2014.

FAGAN, J. Women and drugs revisited: Female participation in the cocaine economy. Journal of Drug Issues, v. 24, Issue 1/2, Jan. 1994, Download by JUSTOR, Mar 2014, p. 179-225.

FELTRAN, G S. Fronteiras de tensão: política e violência nas periferias de São Paulo. São Paulo: Ed. UNESP, CEM, 2011. 360 p.

FRASER, N. Que é crítico na Teoria Crítica? O Argumento de Habermas e o Gênero. In: CORNEEL, Drucilla; BENHABIB, Syla (Coord.). Feminismo como Crítica da Modernidade. Rio de Janeiro: Rosa dos tempos, 1987., pp.38-65. 
FREIRE FILHO, J. Força de expressão: construção, consumo e contestação das representações midiáticas das minorias. Revista FAMECOS, $n^{0}$ 28, dezembro 2005, pp 18-29.

MACHADO, J. A questão da técnica jornalística: cultura e imaginário. DOSSIÊ ESPECIAL: GT Comunicação e Cultura (COMPÓS - 2009), pp.13-18.

LAGO, N. Mulheres na prisão: entre famílias, batalhas e a vida normal. Dissertação (Mestrado), 2014, 95p. Faculdade de Filosofia Letras e Ciências Humanas,Universidade de São Paulo.

LAURETIS, T.. A tecnologia do gênero. Indiana University Press, 1987.

Disponível em: http://pt.scribd.com/doc/81873993/A-Tecnologia-do-Genero-Teresa-deLauretis. Acesso em: Sept. 2013.

MAHER, L. Sexed Work: Gender, Race and Resistance in a Brooklyn Drug Market. Oxford University Press, 1987.

MISSE, M. Malandros, marginais e vagabundos e a acumulação social da violência no Rio de Janeiro. 1999, 413p. Tese (Doutorado), - Instituto Universitário de Pesquisas do Rio de Janeiro, IUPERJ.

MAIA, R. et al. CONVERSAÇÃO E DELIBERAÇÃO SOBRE QUESTÕES SENSÍVEIS: um estudo sobre o uso das razões que circulam nos media.

MAIA, R. Deliberação e Mídia. 2009, cap.3. Disponível em www.compos.org.br. Acesso em: Jan de 2016.

RUGGIERO, V.; SOUTHN. The late city as bazaar: drug markets, illegal enterprise and the barricades. The British Journal of Sociology, v. 48, n. 1, p. 54-70, 1997. Disponível em:http://www.justor.org/ Acesso em: junho de 2013.

SCOTT, J. Gender: a useful category of historical analysis" in: Gender and the politics of history, New York, Columbia Univ. Press (ou na tradução: Gênero: uma categoria útil de análise histórica. Educação e Realidade. 16 (2), jul-dez 1990, pp. 5-22.

SISTEMA INTEGRADO de INFORMAÇÕES PENITENCIÁRIAS - InfoPen, Portal do Ministério da Justiça, Disponível em http://portal.mj.gov.br. Acesso 10 de dezembro de 2012.

SENA, L. L. O crack como fenômeno midiático: demônios e silêncios. Revista Dispositiva, no. 2, 2012, pp.122-146.

SENA, L. L.. I Love my White: mulheres no registro do tráfico ilegal de drogas. Tese (Doutorado) 2015, 187p. Programa de Pós Graduação em Ciências Sociais da Pontifícia Universidade Católica de Minas Gerais. 
STEFFENSMEIER, D.; ALLAN, E.. Gender and crime: toward a Gendered Theory of Female Offending. Annual Reviews of Sociology, n. 22, 1996, p. 459-487. Disponível em: www.annualreviews.org. Acesso em: 13 maio 2014.

TELLES, V. S. A cidade nas fronteiras do legal e ilegal. Belo Horizonte: Fino Traço, 2010.

TELLES, V. S. Ilegalismo populares e relações de poder nas tramas da cidade. In: CABANES, Robert; GEORGES, Isabel; RIZEK, Cibele; TELLES, Vera da Silva (Org.). Saídas de emergência: ganhar/perder a vida na periferia de São Paulo. São Paulo: Boitempo, 2011.

WACQUANT, L. O lugar da prisão na nova administração da pobreza. Novos Estudos Cebrap, n. 80, p. 9-19, 2008.

Matérias Citadas retiradas de: $\underline{\mathrm{HTTP}: / / \text { otempo.com.br }}$

Mães levam droga para filhos em cadeia - publicado em 26/08/06

"Mãe colocava filho para vender droga" - publicado em 14/08/2007

Doméstica é presa acusada de atuar com o filho no tráfico - publicado em 23/01/08

"Cozinheira é presa com drogas em Contagem" - publicado em 09/06/08

"Dona de casa é presa e adolescente apreendido com mais de mil pedras de crack em Contagem" - publicado em 14/08/2009

Mãe e filho são detidos com drogas em Betim - publicado em 10/12/09 